\title{
Huge and Unique Pseudomyxoma Peritonei
}

\section{Brahmana Askandar Tjokroprawiro ${ }^{1}\left[\right.$ [ Hari Nugroho ${ }^{1} \cdot$ Birama Robby Indraprasta $^{1}$}

Received: 12 December 2020 / Accepted: 29 January 2021 / Published online: 3 March 2021

(c) Federation of Obstetric \& Gynecological Societies of India 2021

A 52-year-old women with recurrent mucinous ovarian adenocarcinoma stage IIIC came to the hospital with mass in abdomen (Fig. 1). CT scan showed accumulation of mucinous fluid and incisional hernia. Surgery was performed, 21 litres mucinous fluid was evacuated (Fig. 2), peritoneal pocket was found and removed (Figs. 3, 4, 5). The patient

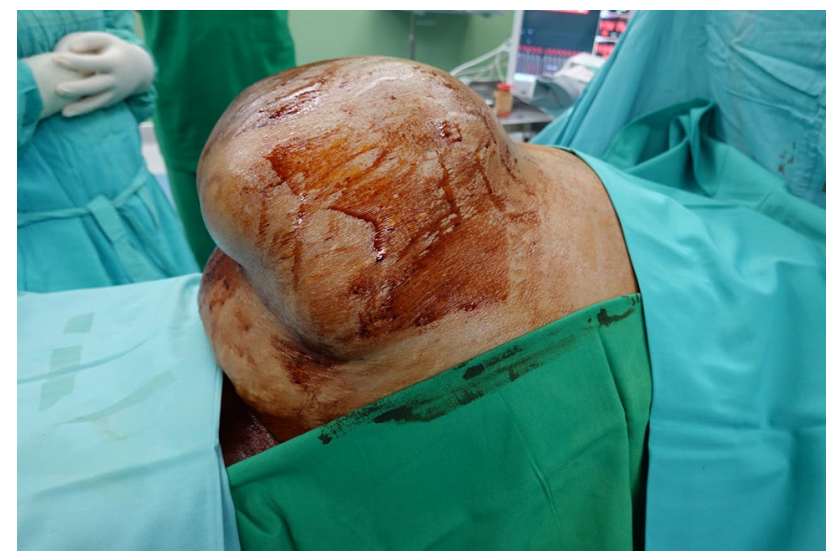

Fig. 1 Enlarged abdomen filled with mucinous fluid

Brahmana Askandar Tjokroprawiro is The head of the department of obstetrics and gynecology, a senior consultant of gynecologic oncology, Dr. Soetomo general academic hospital, Medical Faculty - Universitas Airlangga, Surabaya, Indonesia. Hari Nugroho is a consultant of gynecologic oncology, Dr. Soetomo general academic hospital, Medical Faculty - Universitas Airlangga, Surabaya, Indonesia. Birama Robby Indraprasta is obstetrician and gynecologist, Dr. Soetomo general academic hospital, Medical Faculty - Universitas Airlangga, Surabaya, Indonesia.

Brahmana Askandar Tjokroprawiro

brahmanaaskandar@gmail.com

1 Department of Obstetric and Gynecology, Dr. Soetomo General Academic Hospital, Medical Faculty -Universitas Airlangga, No 6-8, Surabaya 60285, Indonesia recovered well and was discharged from the hospital on day seven after surgery. One month after surgery, patient visited emergency room with complaints of breathlessness. Chest X-ray showed bilateral pneumonia with Covid-19 disease. Patient succumbed due to worsening of the disease.

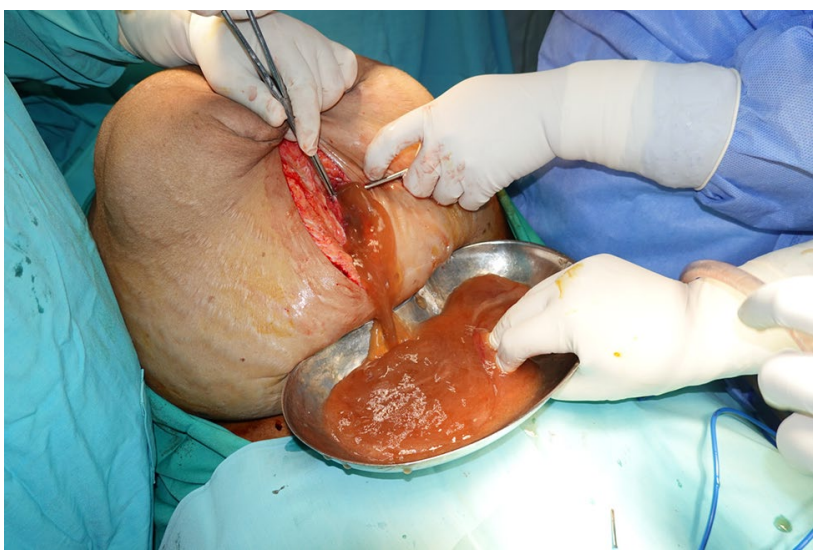

Fig. 2 Twenty one liters of mucinous fluid was evacuated

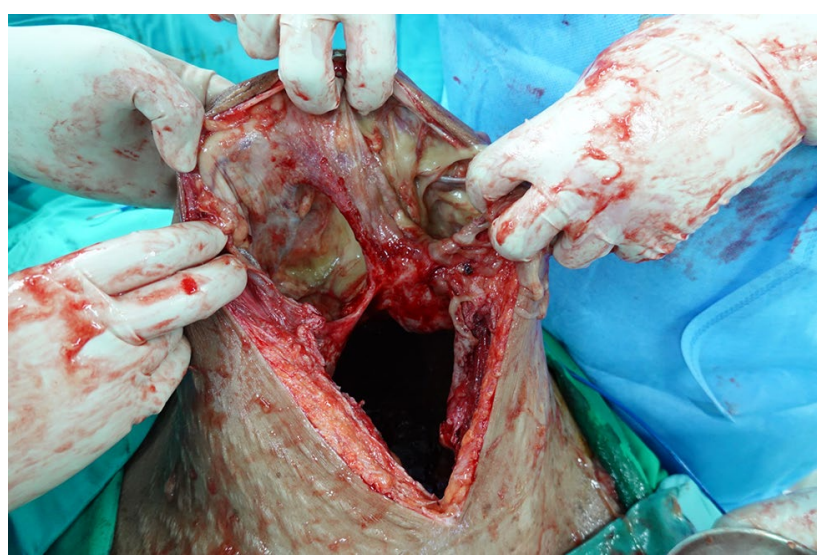

Fig. 3 The peritoneal pockets were also filled with mucinous fluid 


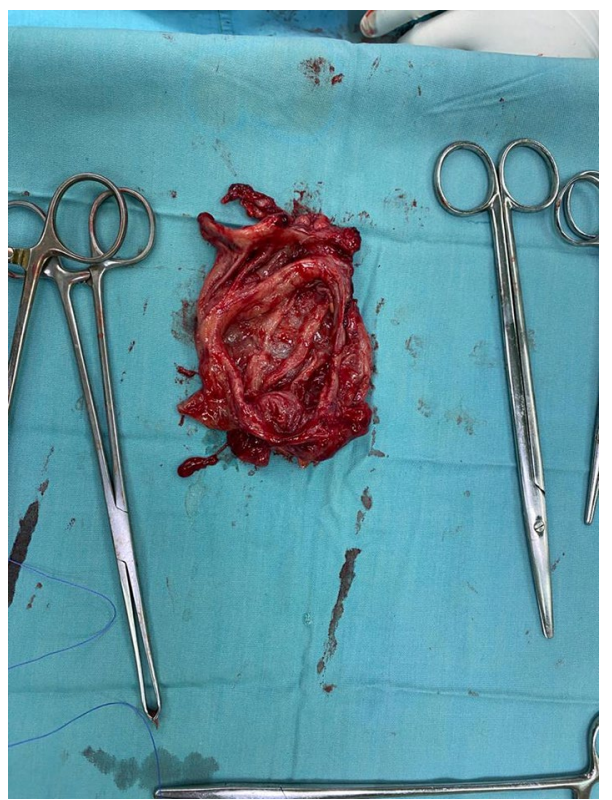

Fig. 4 Peritoneal pockets were removed

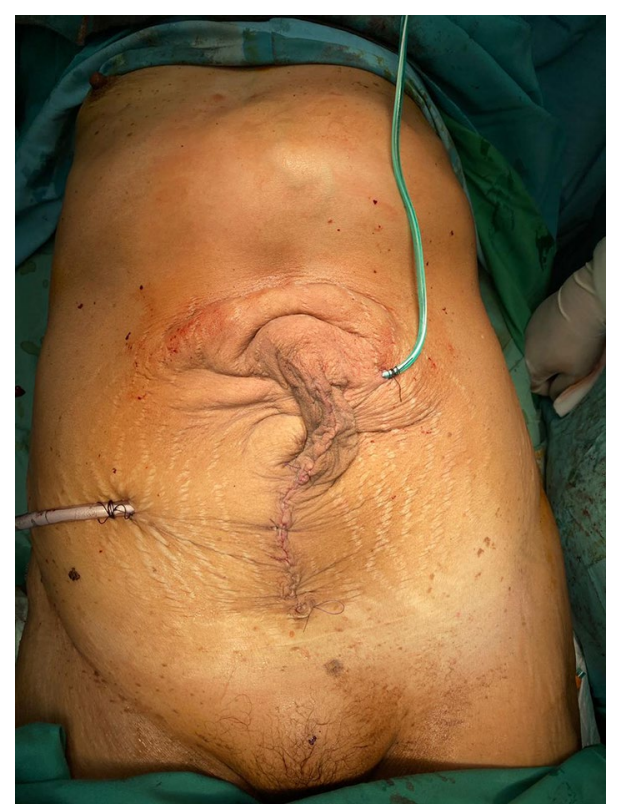

Fig. 5 The abdomen was closed. Two drains were attached
Funding This study did not receive any funding

\section{Compliance with Ethical Standards}

Conflict of interest The authors declare that they have no conflict of interest.

Informed consent A written and informed consent was obtained from the patient informing them about the publication of case and pictures in the journal.

Publisher's Note Springer Nature remains neutral with regard to jurisdictional claims in published maps and institutional affiliations.

\section{About the Author}

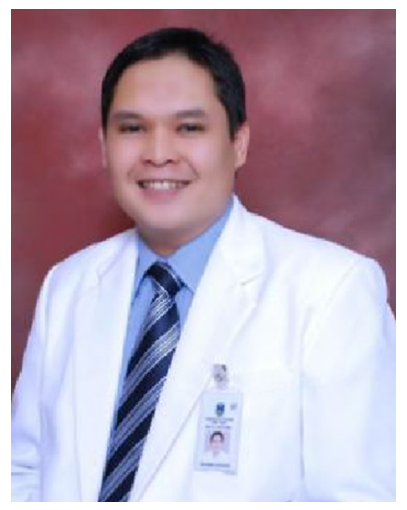

Brahmana Askandar Tjokroprawiro is the head of the Division of Gynecologic Oncology, Dr. Soetomo General Academic Hospital, Medical Faculty - Universitas Airlangga Surabaya. He graduated as a gynecologic oncologist in 2006 from Indonesia University. He is the National Coordinator of Gynecologic Oncology Fellowship Program. He spends a lot of his time teaching, researching and providing services to patients in outpatient clinic and in operating theatre. $\mathrm{He}$ is the Chairman of Indonesia

Medical Association Surabaya branch. 